González Soutelo, S., Gutiérrez Garcia-Moreno, A. y Royo Plumed, H. (2018): “EI sarcófago romano de Tui (Pontevedra): un ejemplo de la presencia de material marmóreo foráneo en el noroeste de la península Ibérica", Spal 27.2: 229-246. DOI: http://dx.doi.org/10.12795/spal.2018i27.21

\title{
EL SARCÓFAGO ROMANO DE TUI (PONTEVEDRA): UN EJEMPLO DE LA PRESENCIA DE MATERIAL MARMÓREO FORÁNEO EN EL NOROESTE DE LA PENÍNSULA IBÉRICA
}

\section{THE ROMAN SARCOPHAGUS OF TUI (PONTEVEDRA, SPAIN): AN EXAMPLE OF A FOREIGN MARBLE MATERIAL IN THE NORTHWEST OF THE IBERIAN PENINSULA}

\author{
SILVIA GONZÁLEZ SOUTELO \\ GEAAT. Universidade de Vigo. Facultade de Historia. Campus Universitario As Lagoas, s/n. 32004 Ourense \\ Correo-e: silviagonzalez@uvigo.es. ORCID: https://orcid.org/0000-0001-8737-8740 \\ ANNA GUTIÉRREZ GARCIA-MORENO \\ Institut Catalá d'arqueologia clàssica (ICAC). Plaça d'en Rovellat, s/n. 43003 Tarragona \\ Correo-e: agutierrez@icac.cat. ORCID: https://orcid.org/0000-0001-8737-8740 \\ HERNANDO ROYO PLUMED \\ Institut Catalá d'arqueologia clàssica (ICAC). Plaça d'en Rovellat, s/n. 43003 Tarragona \\ Correo-e: hroyo@icac.cat. ORCID: https://orcid.org/0000-0003-4719-0748
}

Dedicado a D. Ricardo García Fernández

Resumen: Como parte del proyecto de investigación Marmora Galicia, que pretende analizar la procedencia, uso y distribución del mármol utilizado en época romana dentro del territorio gallego, se ha estudiado el sarcófago marmóreo de Tui, un ejemplar prácticamente inédito. Esta pieza presenta un doble interés: por una parte, es una de las escasas piezas de mármol de gran tamaño presentes en el territorio gallego; y por otra, el estudio arqueométrico e histórico que hemos realizado sobre esta pieza ha permitido la identificación de su materia prima con una procedencia foránea, concretamente del Anticlinal de Estremoz (en el Alentejo portugués). Por lo tanto, su presencia en el noroeste peninsular es significativa para entender la inclusión de este territorio en las redes de comunicación y comercio de este tipo de materiales de época romana.

Palabras clave: sarcófago; mármol; vías de comunicación; spolia; arqueometría; Anticlinal de Estremoz; Gallaecia.

\begin{abstract}
As part of the Marmora Galicia research project, focused on the provenance, use and distribution of marble in Roman times in the territory of modern Galicia, the study of the marble sarcophagus of Tui has been undertaken. Besides being a practically unpublished object, it is also of interest as it is one of the few large-size marble objects found in this territory and its study has confirmed a non-local origin for the marble used to carve it. Indeed, the fact that the marble comes from the Estremoz Anticline (in modern Alentejo, Portugal) adds to the understanding of the communication networks and commerce regarding this sort of Roman materials in the NW of the Iberian Peninsula.
\end{abstract}

Keywords: sarcophagus; marble; communication routes; spolia; archaeometry; Estremoz Anticline; Gallaecia. 


\section{EL SARCÓFAGO ROMANO DE TUI. BREVE HISTORIA DE SU DESCUBRIMIENTO}

En el Museo Diocesano de Tui, población del sur de la provincia de Pontevedra limítrofe con Portugal (fig. 1), se custodia una pieza arqueológica singular, consistente en una caja de sarcófago realizada en mármol veteado rosado. A pesar del interés que esta pieza tiene como elemento funerario de época romana, hasta el momento no había sido objeto de un estudio en detalle, quizás por no presentar ninguna representación escultórica en su superficie que añadiese información sobre su significado, cronología y procedencia. Su importancia si cabe es mayor dada la escasa representación de este tipo de elementos marmóreos dentro del territorio noroccidental de la Península. En ese sentido, debemos recordar que, junto al ejemplar de Tui, en Galicia solo se han identificado los sarcófagos romanos y tardorromanos del conde Santo de Lourenzá, el de Sta. Comba de Bande, un lateral de sarcófago en Portosín -Goiáns, Porto do Son-, así como una tapa de sarcófago con motivo cristiano reutilizada en la iglesia de Sta. María de Temes -Carballedo-.

El sarcófago que nos ocupa ingresó en el Museo Diocesano de Tui con probabilidad en 1974 (fecha de fundación de esa institución), con el número de inventario 367. Procedía de la exposición existente en el claustro de la Catedral de Tui, conjunto edilicio fundado en el s. XII, situado a escasos $100 \mathrm{~m}$ del museo, en donde se están habilitando las nuevas instalaciones para el traslado de la colección. Sin embargo, su procedencia original no deja de presentar dudas, puesto que si bien hay autores que consideran que fue el sepulcro utilizado para enterrar al santo patrón de la ciudad de Tui (Lopes Frazão da Silva 2017), Fr. Pedro González, fallecido según las crónicas en 1246 (Flórez 1767a: 129; Flórez 1767b: 143), la certeza sobre su uso y lugar de descubrimiento no deja de ser meramente circunstancial.

En ese sentido, Ambrosio de Morales en el s. XVI (Flórez 1765: 142-144) hace una posible referencia a este sarcófago al describir las vicisitudes que vivió el cadáver del santo. Así se documenta que, aunque inicialmente habría sido enterrado por mandato del obispo D. Lucas de Tui «entre el coro de la Catedral y su puerta principal», unos siglos más tarde, concretamente el 22 de enero de 1529, el obispo D. Diego de Avellaneda lo desenterraría, tomaría las reliquias y las depositaría en una urna de madera forrada de plata. Así describe el episodio el padre Flórez (1767b: 172-175):
El obispo D. Diego de Avellaneda, teniendo deseo de honrar este santo, determinó sacarlo de alli donde estaba antes sepultado. Halló resistencia en muchos de su Capitulo, más a fin una noche después de Maitines con algunos capitulares hizo quitar la lauda y cavar la sepultura. A medio estado se halló otra lauda con que el Obispo se regocijó mucho pensando estaba luego debajo della el bendito cuerpo. Quitada la piedra se halló tierra maciza, por donde los Canónigos de contrario parecer le convencian de que no cabase más. El obispo también con lágrimas en los ojos, manifestó su congoja, más perseverando en su devoción, mandó cabar adelante hasta otra tercera lauda que se descubrió a otro estado de hondo. Quitada ésta, apareció un encaje de cuatro maderos muy gruesos, $y$ dentro de ellos en arca de piedra el bendito cuerpo con su hábito negro y blanco y su báculo (...).

Desde entonces, las reliquias del santo pasarían a custodiarse en la nueva capilla de S. Telmo o Capilla de los Obispos (Ávila y la Cueva 1852: 321), conocida actualmente como Capilla del Santísimo Cristo de la Agonía (Seara 2015: 102). Sin embargo, si es correcta la identificación del "arca de piedra" con el sarcófago objeto de estudio en el que según la tradición fue enterrado S. Telmo (como así nos indicaron diversos responsables de la Sta. Iglesia Catedral de Tui), no tenemos más referencias sobre su descripción, reutilización o traslado en fechas posteriores, ni en relación con su colocación en el claustro catedralicio junto con otros sarcófagos graníticos procedentes del entorno, hasta su trasladado definitivo al Museo Diocesano de Tui, ya en el último cuarto del s. XX.

Fuese o no ese el origen de su hallazgo, lo que nos proporcionaría este hecho en todo caso es una datación ante quem de mediados del s. XIII. Sin embargo, desconocemos la procedencia precisa de ese sarcófago marmóreo romano y el momento concreto de su llegada a esta población. Así, si bien entendemos que este elemento es de época romana, las dudas surgen sobre el momento de traslado al Noroeste peninsular, ya que si, como veremos, pudo producirse en época romana o tardorromana, no es un hecho infrecuente la llegada de este tipo de monumentos desde otros yacimientos o áreas más alejadas y su posterior reutilización ya en época medieval e incluso moderna.

Evidentemente, la hipótesis de su presencia en el enclave tudense en época romana se sustenta en el hecho de que este núcleo urbano tuvo desde época antigua una notable preeminencia como eje de comunicaciones y como uno de los principales asentamientos romanos del Noroeste peninsular (Pérez Losada 2002: 61). En efecto, en relación con esta población se han 
documentado no solo significativas referencias al enclave Tude en los itinerarios y autores clásicos (Plin. HN, IV, 112 o Ptol. Geog. II, 6, 44, respectivamente, en referencia al castellum Tyde y a Tudae -entre el populus de los grovios-; en el It. Ant. 429, 4 o An. Rav. 307, 17, mencionado como Tude; o en los miliarios de la vía XIX -IRG III 3; EE VIII 209-), sino que también se han localizado abundantes muestras constructivas, epigráficas y arqueológicas que avalan su relevancia, dada cuenta del hecho de que Tui ocupa una posición estratégica esencial, tanto por línea viaria como marítima-fluvial (Pérez Losada 2002; González Soutelo y Cendón Fernández 2006; González Soutelo 2007).

Así, este enclave cumplía un papel significativo como puerto fluvial al que llegaba el comercio marítimo a través del río Miño (algo identificado no solo para época romana -Naveiro López 1991: 138-139; Fernández Fernández 2013: 66; Carlsson-Brandt y Fernández Abella 2013; González Soutelo y Pérez Losada 2014 sino fundamentalmente en época medieval, como uno de los principales puertos interiores del sur de Galicia -Iglesias Almeida 1988; Ferreira Priegue 1991-). Igualmente, por Tui pasaba, tras cruzar el río Miño, el trazado de la vía romana que desde Bracara Augusta se dirigía a Lucus Augusti a través de la Depresión Meridiana (identificando en este enclave la mansio Tude de la vía XIX del Itinerario Antonino). Dicha posición estratégica, sin duda, incidió en el desarrollo económico y monumental de este asentamiento, como aparece bien representado en los múltiples restos arqueológicos de época romana y tardorromana, que ya desde el s. XVI se fueron documentando en la ciudad y en el entorno inmediato.

Fue también, sin duda, su relevancia político-administrativa y económica dentro del ámbito meridional gallego, al menos desde época romana, lo que condujo a la temprana fundación de la sede episcopal tudense en este mismo lugar, ya en el s. VI d.C. (mencionada en el Parrochiale suevum XII; y en referencias a sus obispos desde el Concilio II de Braga; o los Concilios IV y VI de Toledo: Flórez 1767a: 27-29), creación de transcendental importancia para el posterior desarrollo de la ciudad de Tui en su actual ubicación (ss. XI-XII), y para la organización del territorio y el desarrollo histórico de esta región durante los siglos siguientes.

Sin embargo, como hemos comentado, debemos citar algunos ejemplos de importaciones de estos materiales al territorio gallego en época posterior, como el caso del sarcófago marmóreo de Vilanova de Lourenzá, que a pesar de estar datado en el s. VI d.C., se documenta que fue traído desde la zona aquitana para servir de sepulcro al conocido como Conde Santo ya en el

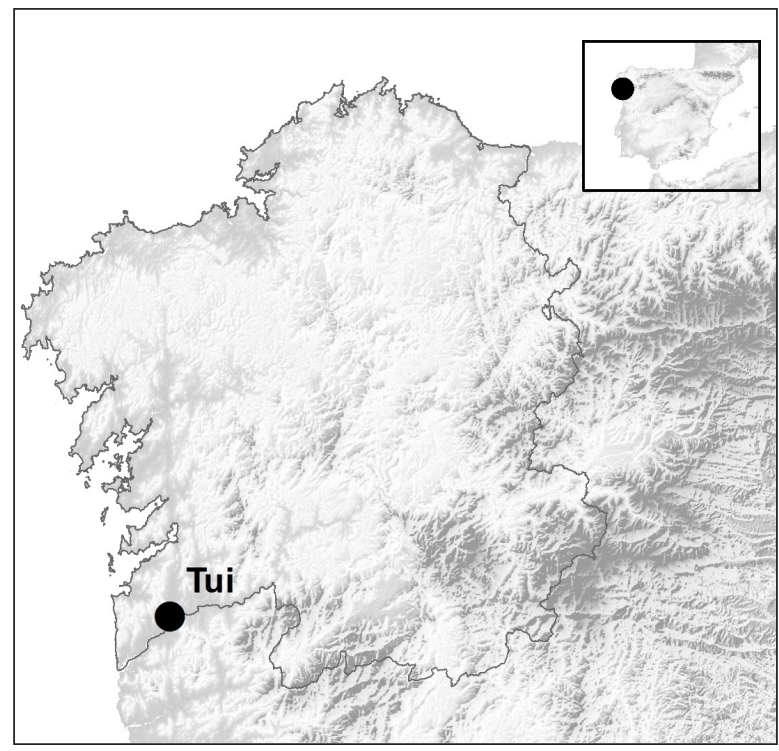

Figura 1. Localización del enclave romano de Tude (Tui).

s. X (sobre esta pieza y su contexto ver, fundamentalmente, Sotomayor Muro 1991; Arias Vilas 1991; González Paz 2009). Igualmente, se conoce la importación de materiales marmóreos desde el ámbito de Coria (Extremadura) hasta Santiago de Compostela en el s. IX d.C. por el rey Alfonso III, para enriquecer la ornamentación de la iglesia dedicada al apóstol Santiago, según relata el Acta de Consagración de la basílica alfonsina del año 899 (Suárez Otero 2003: 57-59; Sánchez Pardo 2015: 105); o bien, el caso de los materiales expoliados del ámbito territorial de Braga ya en el s. XII por el arzobispo D. Gelmírez para su posterior traslado a Santiago en el s. XII, indicando expresamente el paso de estas reliquias por S. Bartolomé de Tui (según relata la Historia Compostelana: Falque 1994: 96-99; Fandiño 2017). Existen igualmente otros materiales marmóreos de importación que hemos documentado en Galicia, en los que surge la misma duda sobre el momento de llegada a la región, como sucede en el caso del sarcófago marmóreo de Sta. Comba de Bande, materiales, todos ellos, actualmente en proceso de estudio.

\section{CARACTERÍSTICAS FORMALES DEL SARCÓFAGO TUDENSE Y ANÁLISIS ARQUEOMÉTRICO}

En la búsqueda de nueva información que aportase luz a la interpretación y comprensión de esta pieza, en el año 2012, en el contexto del proyecto de investigación 
sobre los materiales marmóreos de época romana y tardorromana presentes en Galicia que estamos llevando a cabo, planteamos un estudio integral de este sarcófago para intentar profundizar en aspectos relacionados con su procedencia, cronología y comercio. Así, procedimos al estudio arqueométrico del sarcófago tudense, a partir de la observación in situ del conjunto de la pieza y la toma de una muestra de su material, que nos ha permitido caracterizar con precisión su origen, aspecto que ha dado pie a estudiar esta pieza desde una perspectiva interdisciplinar que proporciona nuevos datos sobre las rutas de transporte y comercio establecidas con el Noroeste peninsular.

\subsection{Descripción formal y paralelos}

Estamos ante una pieza monumental realizada íntegramente en un único bloque marmóreo blanco de característico veteado rosado. Presenta unas dimensiones interiores de 185 × 50 x $53 \mathrm{~cm}$, con paredes de $5 \mathrm{~cm}$ de grosor, lisas y pulimentadas exteriormente, sin decoración alguna. La base, por su exterior, no está trabajada, conservando las marcas de las labores originales de extracción y preparación del bloque en la cantera, incluyendo también en su interior signos de repicado.

Los ángulos exteriores mantienen la forma rectangular con arista viva, mientras que en el interior sus cabeceras aparecen redondeadas. En términos generales, aunque no se conserva la tapa (si es que la tuvo), muestra un estado de conservación aceptable si exceptuamos una fractura con rebaje en una de las paredes laterales (fig. 2).

Así, el sarcófago de Tui presenta unas características formales bien definidas que permiten incluirlo dentro del grupo de los sarcófagos simples o "de bañera", según la consideración de autores como Mateos Cruz (1999). Este tipo de sarcófagos sería destinado principalmente a ser enterrado, frente a los ejemplares ornamentados que, dada su narrativa, serían mayoritariamente expuestos de forma exenta en sus correspondientes mausoleos (Cagnat y Chapot 1916: 331-332). Los ejemplares de esta tipología de sarcófagos aparecen bien representados en el yacimiento de Sta. Eulalia de Mérida, en donde aquellos ejemplares marmóreos de similar realidad formal aparecen definidos como «sarcófagos de forma rectangular, con esquinas redondeadas en el interior (...), en los que sus caras se encuentran alisadas tanto en el interior como en el exterior» (Mateos Cruz 1999: 55) (fig. 3).

Como veremos, la referencia a esta descripción no está hecha al azar, ya que, por su caracterización formal y material, como veremos, los principales paralelos al sarcófago de Tui que hemos identificado hasta el momento se centran en el territorio lusitano, vinculados al ámbito de la ciudad romana de Emerita Augusta y su entorno.

\subsection{Análisis arqueométrico}

Un aspecto fundamental para ahondar en la comprensión de la pieza tudense es la caracterización de la materia prima en la que fue elaborada. Si bien es obvio que se trata de un sarcófago realizado en mármol, hasta el momento no se había llevado a cabo su caracterización arqueométrica, paso esencial para identificar la procedencia de este mármol como dato imprescindible a la hora de reconocer aspectos tan interesantes como son los procesos de producción y circulación de este tipo de piezas. Pero el interés de los estudios de procedencia va más allá de lo que concierne específicamente a la comprensión de un determinado objeto en particular. En efecto, desde una perspectiva mucho más global, la identificación de los mármoles permite asimismo entender aspectos socioeconómicos de la sociedad romana, puesto que «rehacer la historia del mármol es, muchas veces, rehacer la historia de los pueblos de la Antigüedad inmersos en laboriosas faenas de extracción del material, trabajos a pie de cantera, comercialización del producto y elaboración final en el lugar de destino o de utilización» (Lapuente y Álvarez 2012).

En concreto, para la caracterización arqueométrica del sarcófago que nos ocupa, se ha aplicado un protocolo multi-método y se han valorado los resultados de varios análisis en conjunto en una aproximación "paso a paso" (Lapuente 2014; Royo 2016). Evidentemente, esta caracterización resulta más completa cuantas más técnicas se apliquen. En este caso, se ha valorado la petrografía macro y microscópica, el estudio de catodoluminiscencia y la espectrometría de masas de las relaciones isotópicas de carbono y oxígeno estables $\left({ }^{13} \mathrm{C} /{ }^{12} \mathrm{C}\right.$ y $\left.{ }^{18} \mathrm{O} /{ }^{16} \mathrm{O}\right)$, que han sido seleccionadas por su potencial discriminante.

El primer paso consistió, pues, en el análisis visual de la pieza in situ, realizado en 2012. Si bien la caracterización e identificación de los mármoles blancos precisa obligatoriamente de la aplicación de técnicas de análisis, esta primera evaluación visual del conjunto de características del mármol es clave y consiste en la observación de propiedades físicas (tamaño de grano cualitativo, color/tonalidades, uniformidad litológica, fracturación, brillo y transparencia, etc.), que 


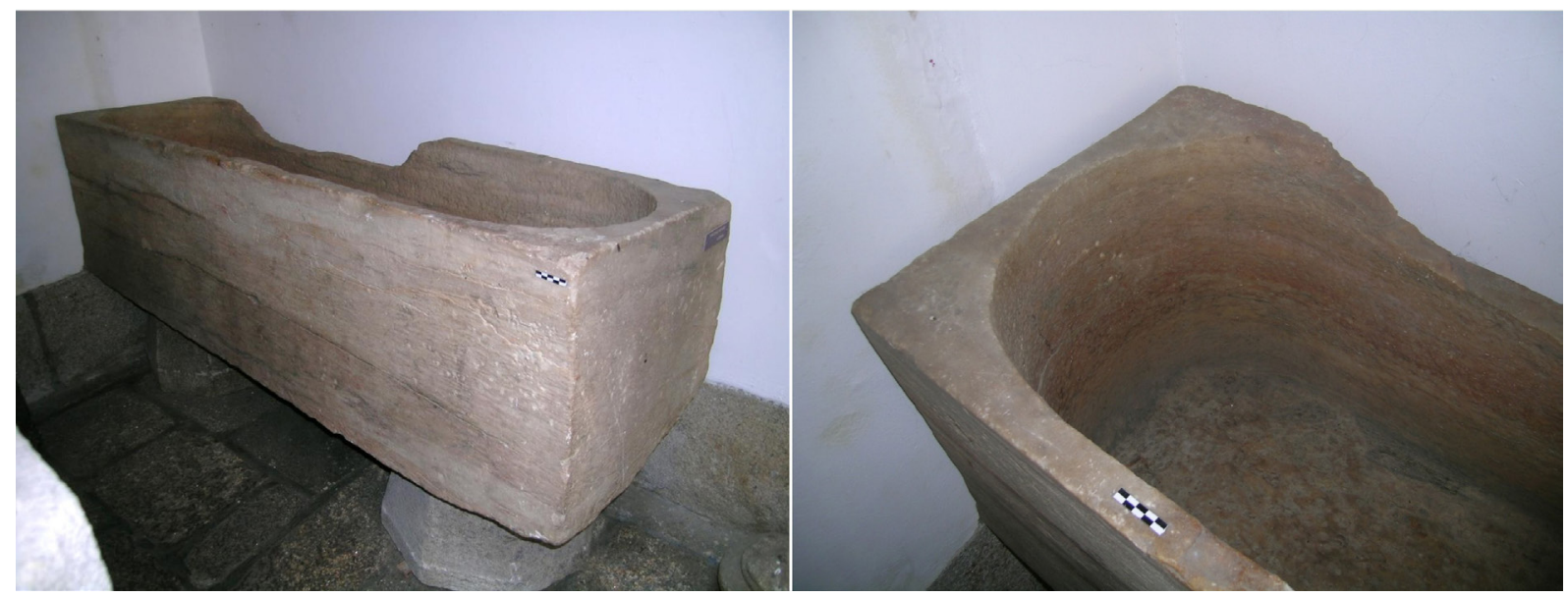

Figura 2. Aspecto visual del sarcófago (Inv. $\mathrm{n}^{\circ}$ 367) depositado en el Museo Diocesano de Tui. Detalle de la talla del interior del sarcófago con la cabecera redondeada (derecha). Foto inferior: foto de detalle en su anterior ubicación dentro del museo Diocesano (año 1999). Fotos autores.

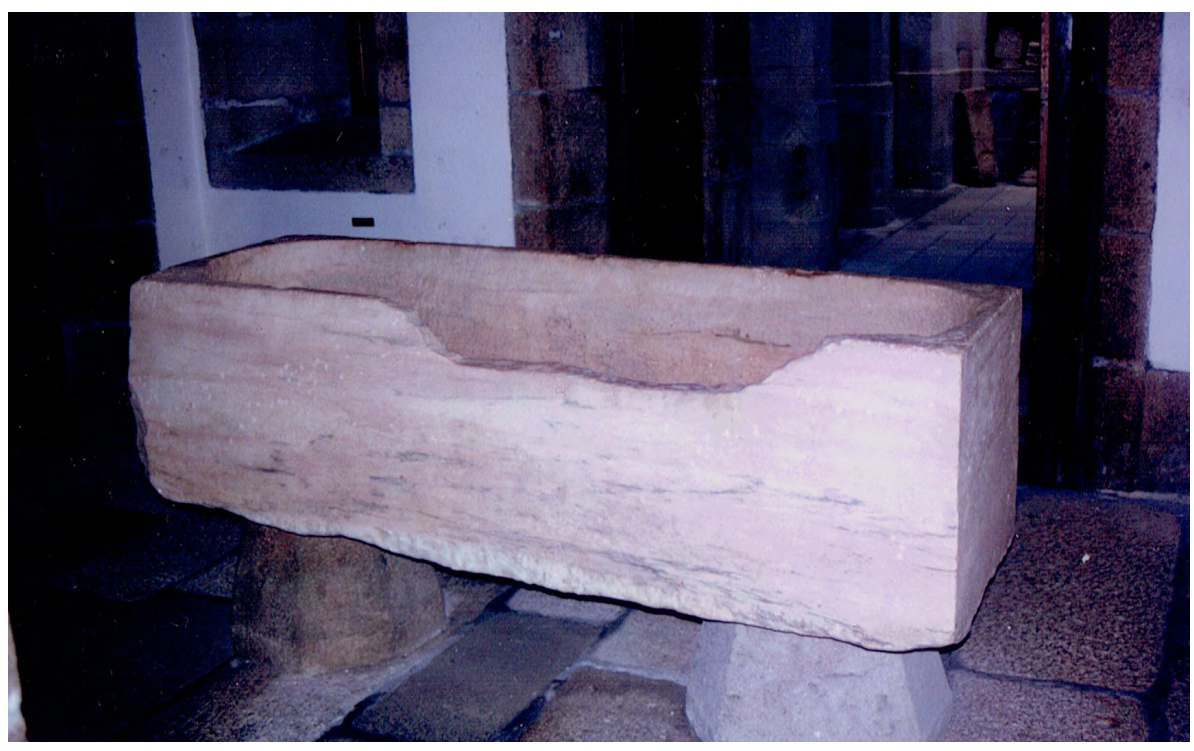

fundamentalmente atienden a la composición mineral y que permiten una primera clasificación. El tamaño de los cristales del mármol, por ejemplo, permite una diferenciación preliminar entre los mármoles de grano grueso $(>2 \mathrm{~mm})$ y los mármoles de grano medio-fino $(<2 \mathrm{~mm})$ que, relacionado con las condiciones de grado de metamorfismo alcanzado, el color/tonalidades y la presencia de veteados, bandeado o laminaciones, hace posible una primera discriminación.

Una vez examinada la pieza, se procedió a la toma de una muestra de aproximadamente $1 \mathrm{~cm}$ de superficie y varios milímetros de grosor, de una zona situada en la base del sarcófago (fig. 4). Esta zona se eligió por ser representativa de la litología del mármol y, a la vez, porque no afectaba al valor escultórico de la pieza; es decir, la muestra se extrajo de un punto de su superficie inferior en donde existía una fractura anterior, evitando así alterar las caras que conservan trabajo antiguo, y donde el mármol no presentaba vetas o puntos alterados/erosionados que pudieran perturbar los valores analíticos. De la muestra tomada, una parte sirvió para elaborar una lámina delgada de $30 \mu \mathrm{m}$ de grosor, imprescindible para su análisis petrográfico y por catodoluminiscencia. Su preparación fue realizada en el Laboratorio de Preparación de Láminas Delgadas del Departamento de Geología de la Universidad Autónoma de Barcelona (UAB). El resto de la muestra se pulverizó en el laboratorio para poder ser utilizada en los análisis geoquímicos previstos, eliminando la parte superficial meteorizada.

El estudio petrográfico microscópico se realizó mediante un microscopio óptico de luz polarizada (Nikon Eclipse 50i POL, a 30x, 60x y 150x con una cámara Nikon CoolPix 5400 para la toma de microfotografías), 

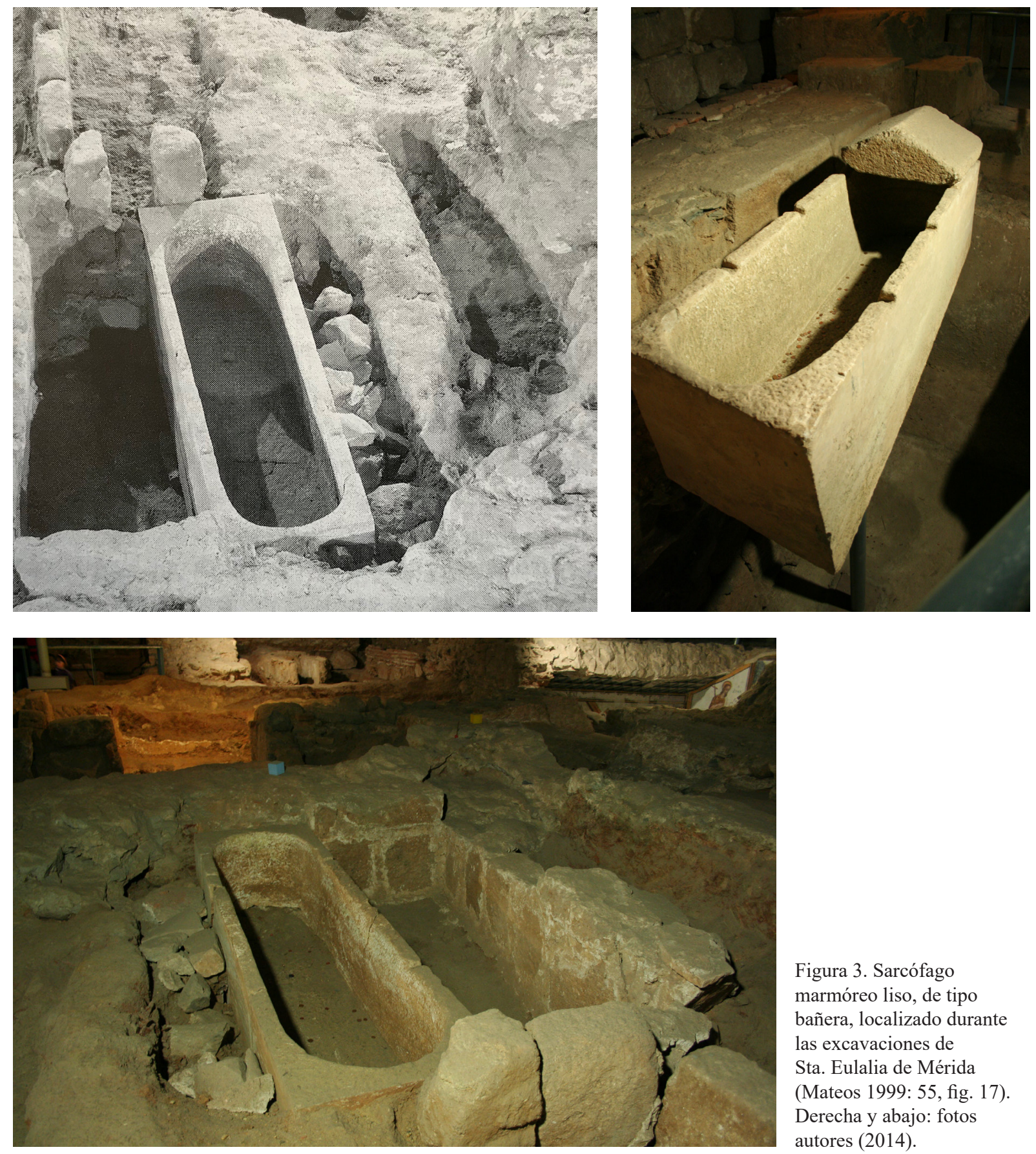

Figura 3. Sarcófago marmóreo liso, de tipo bañera, localizado durante las excavaciones de Sta. Eulalia de Mérida (Mateos 1999: 55, fig. 17). Derecha y abajo: fotos autores (2014).

con el objetivo de determinar no solo la composición mineralógica del mármol -mediante la observación del comportamiento óptico que presenta cada mineral-, sino también aspectos texturales-microestructurales y granulométricos de gran interés para el reconocimiento del material pétreo, como la textura, fábrica, tamaño máximo de grano (o MGS: Maximum Grain Size), forma de los límites de grano (o GBS: Grain Boundary Shape), tipos de maclas (según la categorización de Ferrill et al. 2004) y presencia/ausencia de deformación intracristalina (Weiss 1954; Herz 1955; Lazzarini et al. 1980; Moens et al. 1988; Burkhard 1993; Capedri y Venturelli 2004). Estos parámetros son discriminantes en combinación con los resultados del análisis 


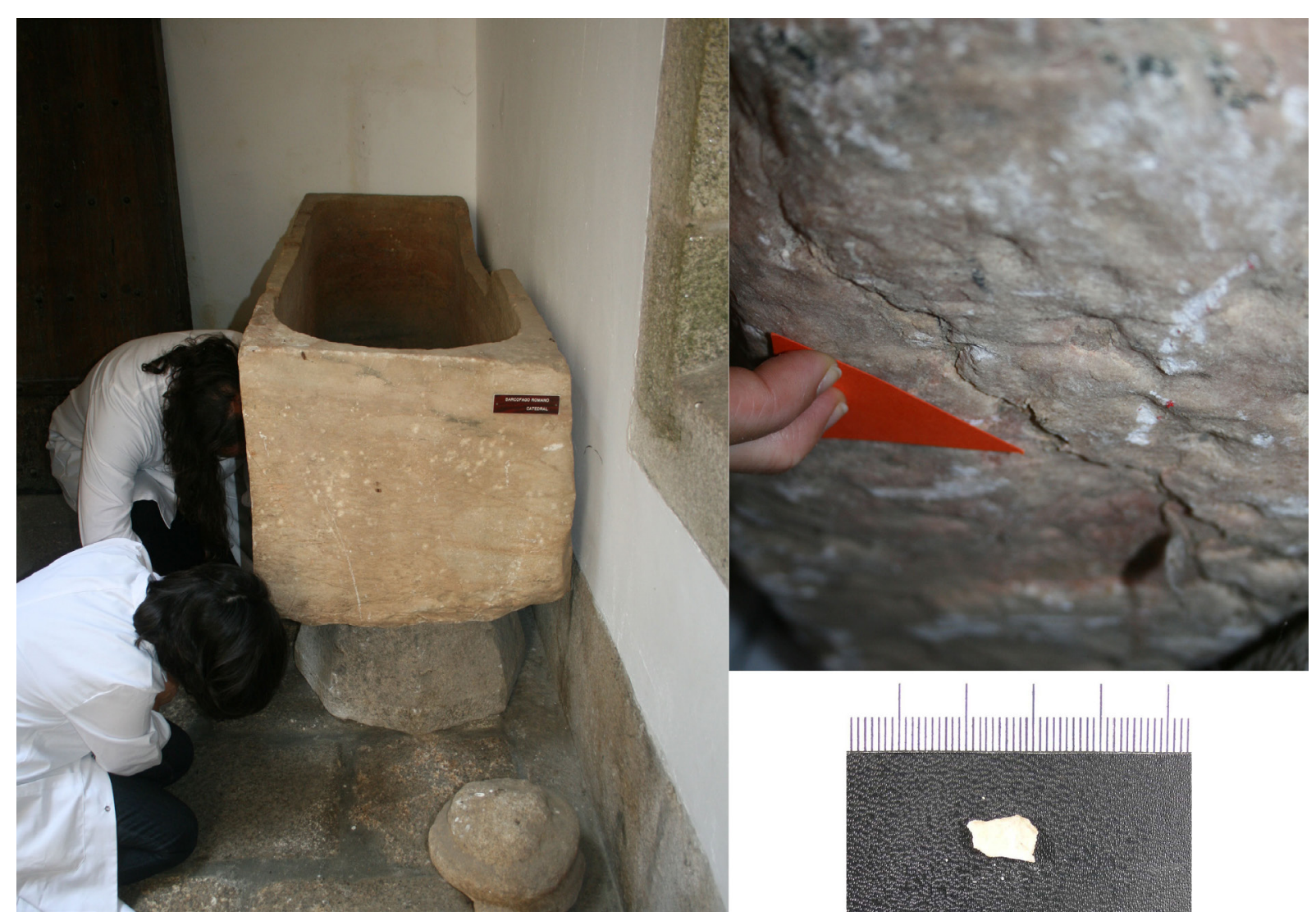

Figura 4. Fotografías de la toma de muestra, en la base del sarcófago (izquierda); de la zona muestreada con indicación del punto de extracción (flecha roja, imagen superior derecha) y del fragmento tomado (imagen inferior derecha). Fotos autores.

por catodoluminiscencia, que se basa en la capacidad luminiscente que presentan los carbonatos, en función de la concentración de algunos elementos traza presentes en la red cristalina - como el $\mathrm{Mn}^{2+}$ - o de la presencia de iones inhibidores -como los $\mathrm{Ni}^{2+}$ y $\mathrm{Co}^{2+}$ - al ser bombardeados directamente por un haz de electrones en condiciones de vacío. La respuesta luminiscente se ha observado con el dispositivo Citl CL8200 Mk5-1 acoplado a un microscopio de luz polarizada Nikon Eclipse 50i POL de la Unidad de Estudios Arqueométricos (UEA) del ICAC. Esta técnica se ha aplicado para su caracterización atendiendo al comportamiento luminiscente de la muestra en función de los parámetros de color, intensidad y distribución particular (Machel 1985; Machel et al. 1991; Habermann et al. 1998; Barbin et al. 1989; Barbin et al. 1992; Blanc 1996; Blanc 1999; Casenave et al. 2003 y Lapuente et al. 2000).

La espectrometría de masas de relación isotópica permite el análisis de las relaciones isotópicas de los elementos ligeros (entre los que se encuentran los que forman parte de los componentes del mármol, es decir
${ }^{13} \mathrm{C} /{ }^{12} \mathrm{C}$ y ${ }^{18} \mathrm{O} /{ }^{16} \mathrm{O}$ ) lo que ayuda a diferenciar mármoles difícilmente distinguibles a simple vista, como es el caso de los blancos, formados en distintas regiones, en momentos cronológicos específicos y cuya historia geológica puede haber desarrollado características isotópicas concretas y diagnósticas. El análisis isotópico se ha realizado en el Laboratorio di Isotopi stabili del Istituto di Geologia Ambientale e Geoingegneria IGAG-CNR) en Roma por M. Brilli, con un espectrómetro de masas de relaciones isotópicas-IRMS GasBench II, previa preparación (pulverización) de la muestra.

Los resultados se expresan en notación delta $(\delta)$ habitual $\delta^{13} \mathrm{C}$ and $\delta^{18} \mathrm{O}$ mediante la relación de esta proporción en la muestra, en tantos por mil (\%o) respecto al estándar internacional PDB (Pee Dee Belemnite). A día de hoy sigue siendo una de las técnicas más empleadas en los estudios de procedencia de mármoles antiguos, junto con otras complementarias, a pesar del alto grado de solapamiento de los valores relativos de cada una de las procedencias al que se ha llegado desde el gran desarrollo de sus estudios a partir de los años 80 y 90 del 

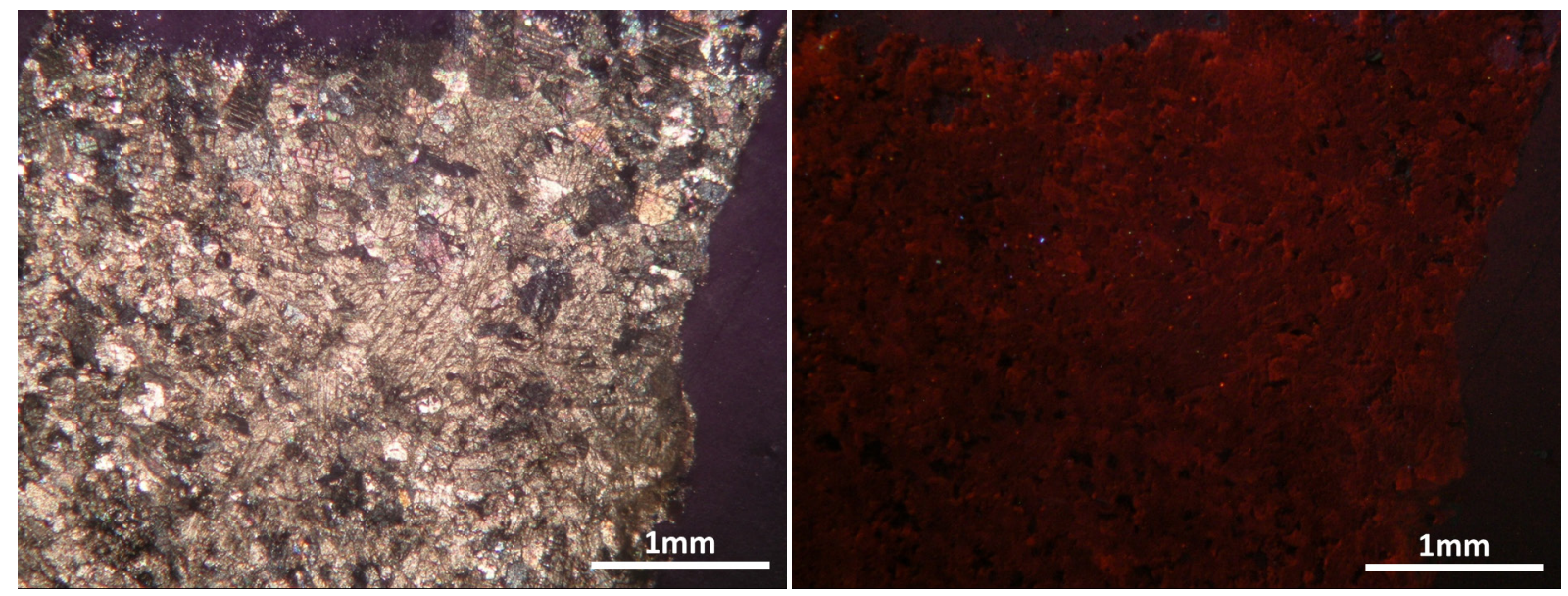

Figura 5. Microfotografías de la muestra TUI-0860: en condiciones de luz polarizada y analizada - LPA (izquierda) y de catodoluminiscencia (derecha).

siglo XX (Gorgoni et al. 2002; Attanasio et al. 2006). El protocolo analítico seguido ha sido el habitual en estos estudios y puede verse, por ejemplo, en Gutiérrez Garcia-M. et al. (2016).

De acuerdo con esta metodología, se aprecia que la pieza está elaborada en un mármol blanco veteado, con gran profusión de vetas rosas y en menor número grises, y un grano de tamaño muy fino. El veteado es subparalelo e irregular y llega a conformar prácticamente la totalidad del material en la parte inferior de la pieza, mostrándose las partes blancas como lentejones aislados. Lógicamente, la pieza fue tallada a partir de un único bloque extraído aprovechando la anisotropía que presenta el mármol, con su lado más largo a favor del veteado. Aunque la pieza presenta una tenue pátina de suciedad, que le da un aspecto anaranjado, el color blanco original y el tamaño de grano se observan claramente en algunos puntos de rotura relativamente recientes. Además, presenta cierto grado de translucidez.

Microscópicamente se trata de un mármol de composición calcítica, fábrica isótropa y textura heteroblástica. Su tamaño de grano es, en efecto, muy fino y heterométrico, con un MGS de 0'7 mm en la muestra analizada. Los cristales están bien trabados y uniformemente distribuidos, presentan unos bordes suturados e interpenetrados, y en menor medida lobulados muy interpenetrados, con maclas finas y no muy bien formadas (fig. 5). Se observan signos de deformación intracristalina como una ligera deformación de maclas en ciertos cristales. De forma accesoria presenta pequeños cristales de cuarzo subredondeados, micas blancas y minerales opacos, junto con una variable cantidad de óxidos de hierro.
El estudio de catodoluminiscencia de la calcita determina una luminiscencia homogénea de intensidad débil y distribución irregular (fig. 5), aunque lo superficial de la muestra afecta a su respuesta generando áreas anómalas de mayor intensidad. Por lo que se refiere a sus valores isotópicos son de $2^{\prime} 0 \%$ en $\delta^{13} \mathrm{C}$ y $-5{ }^{\prime} 6 \%$ en $\delta^{18} \mathrm{O}$ (fig. 6).

El análisis comparativo de estos resultados con muestras de roca tomadas en diferentes canteras o frentes de explotación, depositados en las colecciones del Laboratorio para el Estudio de los Materiales Lapídeos en la Antigüedad (LEMLA) de la Universidad Autónoma de Barcelona (UAB), de la litoteca de Petrología de la Universidad de Zaragoza (Unizar) y del Institut Català d'Arqueologia Clàssica (ICAC), a los cuales se han aplicado las mismas técnicas analíticas que las usadas para el mármol del sarcófago de Tui, así como su cotejo con los valores de referencia actualizados de los principales mármoles empleados en época antigua, publicados en numerosos trabajos (entre los que destacan Lazzarini et al. 1980; Herz 1987; Moens et al. 1992; Attanasio et al. 2006; 2015; Barbin et al. 1992 y las actas de los varios congresos internacionales de la Association for the Study of Marbles and Other Stones in Antiquity (ASMOSIA): Herz y Waelkens 1988; Waelkens et al. 1992; Maniatis et al. 1995; Schvoerer 1999; Herrmann et al. 2002; Lazzarini 2002; Maniatis 2009; Jockey 2009; Gutiérrez Garcia-M. et al. 2012; Pensabene y Gasparini 2015), es lo que permite proponer una procedencia para el mármol en estudio.

En este caso, además, se han tenido en cuenta los valores de referencia de los mármoles hispanos, cuyo estudio durante las últimas décadas del siglo XX y primeras del XXI ha permitido ampliar de forma significativa la 


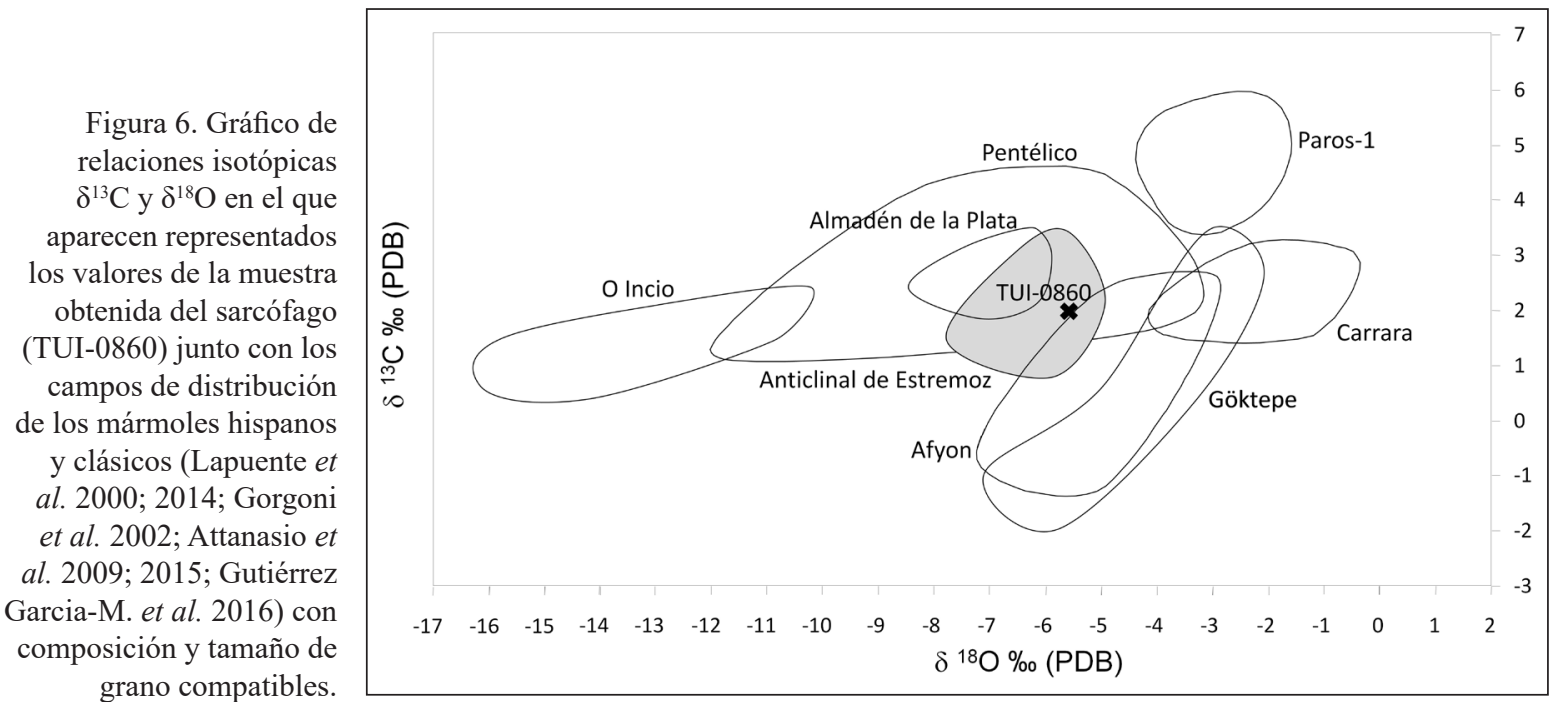

base de referencia disponible (Cabral et al. 1992; Lapuente 1995; Lapuente y Turi 1995; Lapuente et al. 2000; en prensa; Lapuente 2014, entre otros). Cabe asimismo recordar la reciente incorporación de materiales del Noroeste peninsular (Cisneros Cunchillos et al. 2010-2011) y en especial de las canteras gallegas, gracias al proyecto Marmora Galicia ya mencionado. Dada la presencia de afloramientos marmóreos en la región, susceptibles de haber sido explotados en la Antigüedad (Canto 1977-78: 180; Braemer 1986: 301; Cisneros Cunchillos 1988: 56-60) y la confirmación arqueométrica de su empleo gracias a las investigaciones desarrolladas en el marco del susodicho proyecto (Gutiérrez Garcia-M. et al. 2016), no se podía descartar a priori el empleo de un mármol local para la elaboración de este sarcófago.

De entrada, la comparación de los resultados derivados del análisis del sarcófago permite descartar una procedencia de fuera de la Península para este mármol. En efecto, el cotejo con los principales mármoles clásicos de grano fino, especialmente el mármol del monte Pentélico (en la Grecia continental) o el mármol de Afyon (en Turquía), permite desecharlos como posibles procedencias por incompatibilidades petrográficas, tanto microscópicas como macroscópicas y de catodoluminiscencia, ya que a diferencia de este sarcófago, no presentan vetas de color rosado y su luminiscencia es muy heterogénea, con diferencias muy marcadas en su intensidad.

En cambio, sus características son relativamente comunes en los mármoles veteados peninsulares, resultando el aspecto más identificativo la tonalidad rosada de sus vetas, especialmente compatible con el mármol procedente del Anticlinal de Estremoz, cuyos afloramientos pertenecen a la Zona de Ossa-Morena.

Esta identificación se confirma con las coincidencias minero-petrográficas entre esta muestra y los mármoles del ámbito lusitano, y especialmente con los valores isotópicos (fig. 6). Éstos sitúan al sarcófago de Tui justo en el centro del campo de referencia definido para el mármol blanco del Anticlinal de Estremoz y, a su vez, fuera de los campos de referencia correspondientes al mármol de Almadén de la Plata (Sevilla) (Lapuente et al. 2014), que en ocasiones puede presentar también coloraciones y veteados similares pero cuyas características granulométricas y texturales difieren de las que presenta el mármol del sarcófago de Tui. Asimismo, los resultados isotópicos permiten abandonar definitivamente la hipótesis de una procedencia geográfica más próxima para el mármol empleado para realizar el sarcófago, a pesar de la existencia de algunas variedades de mármol con coloraciones rosáceas en el Bierzo (León), en particular en la zona de Ambasmestas, San Fiz do Seo y Tejedo de Sil, puesto que sus valores isotópicos son muy distintos (materiales en proceso de estudio por M.C. Savin -ver agradecimientos-). Entre estos, el único que ha sido caracterizado arqueométricamente con anterioridad es el mármol de color rosa pálido en San Fiz (litotipo L7a), pero las características difieren de manera significativa y no se presentan valores isotópicos (Cisneros et al. 2010-2011).

Las principales explotaciones del Anticlinal de Estremoz cuyo empleo se ha documentado en época romana se encuentran entre las localidades de Estremoz, que da nombre a la formación geológica, y Vila-Viçosa (en un 
área situada al sureste de Portugal) a aproximadamente $120 \mathrm{~km}$ de la ciudad de Mérida y a poco más de $400 \mathrm{~km}$ de distancia, en línea recta, de la ciudad gallega de Tui.

Tal y como las evidencias arqueológicas e históricas nos han ido mostrando, la caracterización del material del sarcófago de Tui viene a confirmar las hipótesis que hemos valorado hasta el momento sobre la identificación de la procedencia de esta pieza, y consecuentemente sobre su importación al territorio gallego desde el ámbito central de la Lusitania.

\subsection{Contextualización a partir de su forma y materia prima}

Apuntado, por tanto, este entorno geográfico e histórico como propuesta, comprobamos que dicha pieza muestra también importantes similitudes con los modelos producidos en canteras lusitanas y que aparecen mencionados, entre otros, por Oleiro (1996) o M. Justino Maciel (1998).

En efecto, estos autores recogen diversas noticias sobre una serie de hallazgos en el ámbito lusitano de Estremoz-Vila Viçosa, zona por excelencia de las canteras de mármol explotadas ya en época romana, relacionados con la presencia de bloques exentos (en este caso, de mármol "blanco anilado rosado") citados posteriormente por otros autores (Fusco y Mañas Romero 2006; Mañas Romero y Fusco 2008; Mañas Romero 2012, entre otros), en cuya superficie aparecieron rebajadas sendas arcas o huecos de sarcófagos en proceso de elaboración y que posiblemente se abandonaron por defectos producidos durante su preparación (fig. 7). Maciel (1998: 238) describe así un bloque irregular de dos cavidades talladas, una de ellas cuadrada y otra ovalada, que fue trasladado al Monte do Olival, freguesía de Glória, concelho de Estremoz (con unas dimensiones interiores máximas de 1'91 x 0’49 x 0’49 m y $7 \mathrm{~cm}$ de espesor de pared); otro bloque de mármol con un único sarcófago oval excavado, proveniente de Monte d'El-Rei, Bencatel; y otro, con similares características, en la freguesía dos Pardais, concelho de Vila Viçosa -y descrito anteriormente por Oleiro (1996-97: 168)-, indicando para el caso de la caja de cabeceras redondeadas, unas dimensiones interiores de 2'05 x 0'52 x 0’6 m. En ambos casos, las piezas en proceso de elaboración presentan unas dimensiones interiores máximas de 1'91 x 0’49 x 0’49 m, que se asemejan en gran medida a las presentes en el ejemplar tudense.

En esos bloques se testimonian parejas de sarcófagos rebajados, con una pared intermedia de escaso grosor, que posiblemente responda al interés por aprovechar al máximo la veta disponible de la que se extraería el bloque marmóreo. Al menos en estos casos, el grosor de sus paredes quedaría muy limitado, lo que descartaría, como sucede en el caso de Tui, la presencia de elementos decorativos de carácter escultórico en sus paredes dada su extrema delgadez.

Según Maciel (1998: 236), el proceso de extracción se vincularía a un sistema de roza y cuñas cuya preparación se completaría en la propia cantera, con el marcado, tallado y desbaste de la forma básica de los sarcófagos en los bloques marmóreos, completando el trabajo con el rebaje exterior por sierra (como se aprecia, por ejemplo, en el bloque procedente de la freguesía de Pardais), tanto para la separación de las unidades, como para conseguir el aspecto paralelepipédico exterior característico. Con el trabajo a pie de cantera se obtendría un mayor rendimiento en el proceso productivo, evitando la exportación de aquellos bloques que revelasen fallos naturales y facilitando el transporte de las piezas finales, que presentarían un peso mucho más reducido.

En todo caso y como veremos por su contexto, se plantea que hacia los siglos III y IV d.C. se produciría un incremento en la producción local de sarcófagos, que podría vincularse a la generalización del rito de inhumación (Maciel 1998) y al posterior contexto políticoadministrativo por el que Mérida se erige como capital de la Diocesis Hispaniarum (Díaz et al. 2007: 73), así como a una nueva etapa de explotación del territorio, en la que se revitaliza el interés por dotarse de materias primas de calidad para la creación de objetos concretos asociados a determinadas necesidades de culto y prestigio, dentro de un contexto paleocristiano.

En ese sentido, otros investigadores como Rodríguez Oliva (2001: 129-133) apuntan también a esa cronología, considerando que en el periodo comprendido entre los ss. III-IV d.C. se generaliza un cambio en el rito de enterramiento, que hace que las necrópolis de la Bética se inunden con sarcófagos de materiales marmóreos locales y/o próximos (caso del mármol Estremoz), de ejecución sencilla, cuya configuración varia muy poco en el tiempo, factor que sin duda dificulta su adscripción cronológica precisa.

Esa datación vendría a ser precisada por los ejemplares localizados en la basílica de Sta. Eulalia de Mérida antes señalados. Así, a raíz de la intervención arqueológica llevada a cabo en el lugar, estos sarcófagos fueron datados, por sus características formales y su posición estratigráfica, entre los últimos años del s. IV y todo el s. V d.C., pudiendo alcanzar en algunos casos hasta el s. VI d.C. (Mateos Cruz 1999: 125-126, 139 y 199). En el estudio de estos ejemplares, el autor 


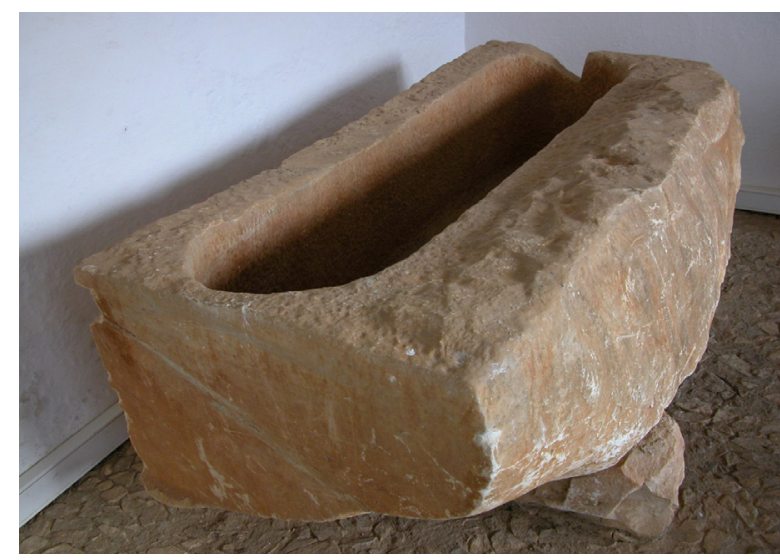

Figura 7. Fotografías de los sarcófagos en proceso de realización localizados en el entorno de Estremoz (Portugal).

Fotos: $7 \mathrm{a}$ (superior izquierda): Bloque con un sarcófago, procedente del Monte d'El Rei, Bencatel, Vila Viçosa, depositado en el Museo de Vila Viçosa (Maciel 1998: Fig. 3. Foto cortesía de I. Mañas); $7 \mathrm{~b}$ (superior derecha): Bloque de mármol con dos sarcófagos rebajados, con las líneas guías de trabajo, procedente de São Marcos, Pardais, Vila Viçosa, depositado en el Museo de Vila Viçosa (Foto cortesía de I. Mañas); 7c (derecha): similar al anterior bloque, en este caso con uno de los sarcófagos en proceso de desbaste, localizado en el Monte do Regoto, Gória, Estremoz - posteriormente trasladado al Monte do Olival- (Maciel 1998: fig. 2).

de la publicación apunta igualmente otros paralelos en territorio hispano, caso de la necrópolis de Sta. Catalina (s. V d.C.), la necrópolis de Tarragona (desde mediados del s. IV hasta el s. VII), o la capilla funeraria de La Cocosa (s. VI d.C.); así como fuera de la Península, con unas dataciones entre los ss. V-VI, para los casos de Tipasa, St. Georges de Viena o St. Laurent D'Aoste, entre otros (Mateos Cruz 1999: 125-126).

Consecuentemente, si ponemos en relación las características formales y estilísticas que aparecen representadas en el sarcófago tudense, en términos generales, consideramos que su datación debe ser igualmente tardía, asociada al periodo tardorromano descrito.

\section{CONCLUSIONES E INTERPRETACIÓN INTEGRADA DE LOS RESULTADOS ANALÍTICOS, FORMALES Y CONTEXTUALES.}

El análisis arqueométrico permite, pues, despejar la primera de las incógnitas planteadas relativas a la procedencia original de esta pieza, ya que verifica la
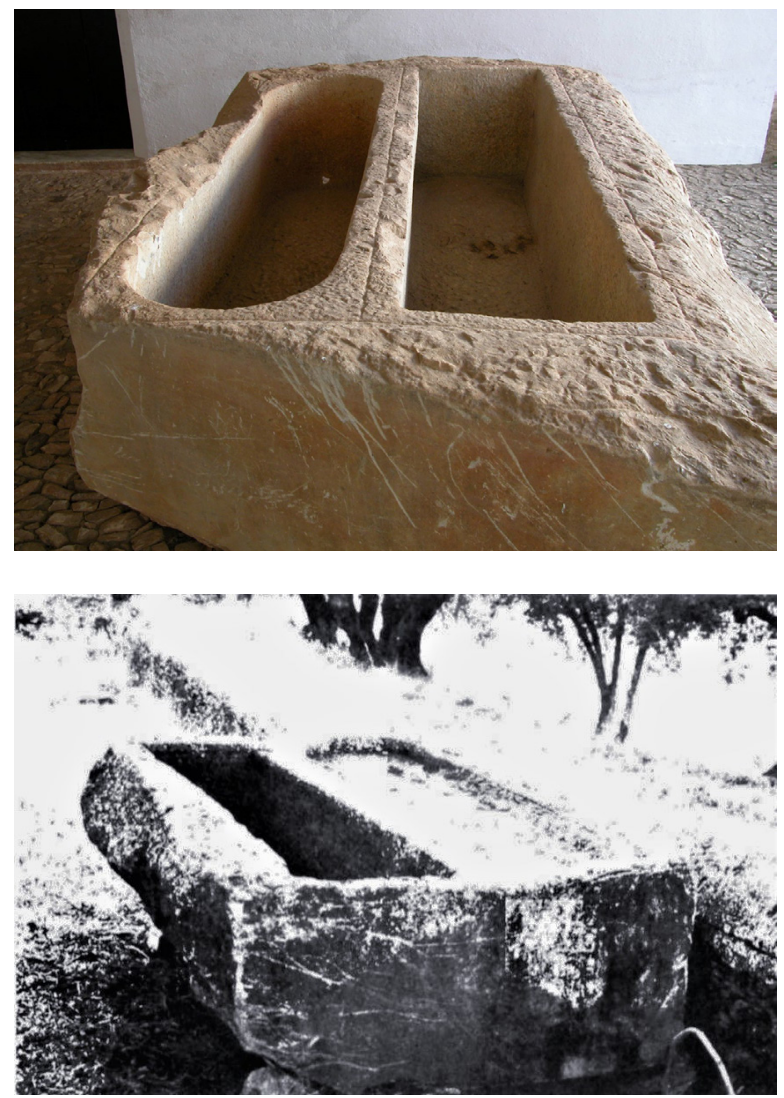

elaboración e importación de esta pieza desde el ámbito central de la Lusitania.

Si bien el transporte de sarcófagos en mármol fue recurrente en la Antigüedad, dados los numerosos ejemplos distribuidos a media y larga distancia ya desde época romana (véase, por ejemplo, el trabajo pionero de J. Ward-Perkins sobre la racionalización y estandarización de la producción de sarcófagos en mármol griego y microasiático -Ward-Perkins 1980a; WardPerkins 1980b-; o las recientes consideraciones sobre la "industria" de los sarcófagos en mármol de B. Russell -Russell 2011; Russell 2013: 256-310-), la importación de este tipo de piezas desde las canteras lusitanas está, hasta la fecha, menos documentada. De ahí la importancia del hallazgo de Tui.

Afortunadamente, este panorama se ha ido modificando en los últimos años. El mejor conocimiento de los parámetros que definen los mármoles del Anticlinal de Estremoz, de gran calidad, ha permitido constatar la presencia de sarcófagos o partes de ellos realizados igualmente en este mármol en varios puntos del norte y centro de la península ibérica, como los descubiertos en el yacimiento de Carranque, Toledo, en donde destaca el 
magnífico sarcófago de Jonás (Fernández Ochoa et al. 2011; García-Entero y Vidal Álvarez 2012); los de Pueblanueva, Toledo (Vidal Álvarez 2016); o los ya mencionados de Ithacio y Revillagigedo en Asturias (Vidal 2007; Vidal Álvarez y García-Entero 2015; Vidal Álvarez et al. 2016). Además, la localización de piezas arqueológicas realizadas en este material en otras áreas de la Península (como Zaragoza, Lapuente et al. 2015; 2016; Nogales et al. 2017) o incluso fuera de la propia Hispania (en Volubilis y Banasa, Antonelli et al. 2009; Antonelli et al. 2015), confirma que la distribución a largas distancias de elementos en este mármol no fue un hecho aislado. El caso de nuestro sarcófago, por lo tanto, debe contextualizarse dentro de este panorama.

Por otro lado, la interpretación cronológica de la producción de esta pieza parece adscribirla a un periodo comprendido entre los ss. IV-V d.C., dada la identificación de paralelos formales en el ámbito inmediato de Emerita Augusta y áreas de canteras en torno a la ciudad de Estremoz, tanto en producción, material y forma.

Sin embargo, la cuestión relativa a su utilización y llegada a la ciudad de Tui no permite una respuesta igualmente concluyente.

Como hemos visto, Tui fue un importante núcleo político y económico de este ámbito del Noroeste peninsular en época romana $y$, por lo tanto, un contexto coherente con la importación de este tipo de materiales. Sin embargo, de acuerdo con la cronología que barajamos para este sarcófago (ss. IV-V d.C., en función de sus paralelos), se pueden considerar diversos momentos de importación.

Por un lado, es posible que se trate de una pieza llegada al Noroeste peninsular en época tardorromana. La presencia en territorio galaico de mármoles procedentes de diferentes partes del Imperio durante este periodo (pongamos, como ejemplo, las esculturas marmóreas de Dionisio y Ampelos y la base con pies, depositadas en el Museo Arqueolóxico Provincial de Ourense, procedentes del yacimiento de Mouradella -Verín-datado en el s. III d.C. Chivite 1964; Fariña Busto 1991; Museo Arqueolóxico Provincial de Ourense 1999; 2006; además de otras piezas que están en proceso de estudio dentro de nuestro proyecto), hace viable que, junto a otras piezas de diferente naturaleza, este sarcófago se incluya como parte de los productos de lujo y autorepresentación demandados por determinadas élites.

No debemos olvidar que hacia los ss. III-IV d.C. se vive un proceso de reorganización territorial. Si bien determinados espacios rurales y urbanos se transforman y llegan incluso a desaparecer, se vive también un momento de concentración del poder y la creación de enclaves vinculados a las nuevas élites, que se materializaría en la transformación y monumentalización de grandes explotaciones rurales (Chavarria Arnau 2008: 195). Ese fenómeno podría detectarse en el ámbito septentrional de la Península, caso de la villa de Veranes (Fernández Ochoa y Gil Sendino 2008: 440) o Toralla (Pérez Losada et al. 2008), entre muchos otros ejemplos que durante ese periodo importan materiales de diversa entidad. Además, la situación estratégica de Tui, tanto en relación con las vías terrestres como con los ejes marítimos y fluviales, permitía comunicar el ámbito costero con zonas de interior, lo que sin duda facilitaría el comercio y la circulación de mercancías desde largas distancias.

El hecho de que el mármol empleado en esta pieza sea de procedencia peninsular, concretamente del ámbito de Mérida-Estremoz, y más si confirmamos la cronología de producción propuesta de acuerdo con los paralelos presentados, refuerza la hipótesis de que ya desde el s. IV d.C. se llevaría a cabo el transporte de este tipo de objetos de prestigio hacia otros ámbitos peninsulares como sería el Noroeste, aspecto que se mostrará en siglos posteriores con la consolidación de las importaciones al ámbito galaico y la plena integración de este territorio en las redes viarias terrestres y marítimas/fluviales existentes entre las antiguas provincias del Imperio.

No obstante, no podemos olvidar que el sarcófago de Tui es un unicum. Aunque existen numerosas necrópolis de época romana y tardorromana en la ciudad de Tui y en sus alrededores, las sepulturas localizadas hasta el momento son todas de tipología simple, basadas en enterramientos de tégula, ladrillos y sillares graníticos, sin referencia alguna a otros sarcófagos monumentales y/o marmóreos.

De ahí que esa cronología pueda ampliarse al periodo de ocupación sueva-visigoda de la ciudad de Tui, dentro del comercio tardoantiguo que se reactivó con fuerza en el Noroeste durante los siglos IV-VII d.C. (Fernández Fernández 2013). Así, este fenómeno podría vincularse, por ejemplo, a las redes comerciales fundamentalmente marítimas, pero también a las diferentes incursiones realizadas por monarcas suevos en su conquista hacia territorios más meridionales del ámbito atlántico (por ejemplo, con la expansión del reino suevo realizada por Rechila que alcanzó y saqueó Mérida en el 440: Díaz et al. 2007: 296), a lo que debemos sumar la posible atracción hacia regiones más septentrionales de materiales de prestigio, que se asociarán, entre otros aspectos, a la fundación de las diferentes sedes episcopales y a la construcción de las iglesias parroquiales. 
Si damos como auténtica la referencia a que este sarcófago se localizó en el contexto de la Catedral de Tui, podría vincularse, no sin dificultades, a su uso en el espacio de necrópolis identificado en el claustro catedralicio (como apunta Rodríguez Colmenero 1993: 418), donde se localizaron diversos enterramientos a los que se atribuyó una cronología de entre los ss. VII-VIII (Martínez Tamuxe et al. 1977, La Voz de Galicia, 13-02-2004; información recopilada en González Soutelo 2007). Desafortunadamente, los procesos de reforma de ese espacio no están documentados y los materiales arqueológicos depositados en el atrio catedralicio (en donde el sarcófago marmóreo estuvo expuesto con anterioridad a su traslado al Museo Diocesano) son en su mayoría de procedencia diversa y desconocida, y de cronología posterior al sarcófago marmóreo, lo que nuevamente dificulta la confirmación del origen de estos materiales en el contexto de la catedral o en sus inmediaciones.

Por último, no habría que descartar la posibilidad de que la presencia de esta pieza en Tui estuviese vinculada a posteriores procesos de traslado y reutilización de objetos marmóreos (spolia). En efecto, este fenómeno fue frecuente en época tardoantigua y altomedieval y un importante número de piezas de mármol llegó a transportarse desde muy diversas procedencias. Esa realidad se constata en otros ejemplos gallegos, como así parece documentarse, y ya hemos comentado, en el sarcófago marmóreo aquitano del Conde Santo de Lourenzá (Lugo), o si tomamos como ciertas las referencias tradicionales sobre el traslado del sarcófago marmóreo de Sta. Comba de Bande desde Guadix con los restos de S. Torcuato huyendo de la ocupación musulmana (Cueva 1991; Caballero Zoreda et al. 2004).

En ese sentido, si bien consideramos la posibilidad de que esta pieza formase parte de los circuitos comerciales tardoantiguos, cabría valorar también su vinculación a nuevos episodios de saqueo y traslado de piezas hacia territorios cristianos, como las rapiñas ya mencionadas asociadas a personajes como el rey Alfonso III o el arzobispo Diego Gelmírez, quienes importaron reliquias y materiales marmóreos desde el ámbito lusitano hasta la ciudad de Santiago de Compostela. De acuerdo con este planteamiento, sería posible apuntar a la introducción de esta pieza en la ciudad de Tui ya en periodo altomedieval, quizás en un momento inmediatamente anterior o coincidente con la tradicional teoría de su reúso como lugar de enterramiento de S. Pedro González Telmo.

Aunque a día de hoy no dispongamos de datos concretos que permitan decantarse por una $u$ otra opción en lo que se refiere al momento de llegada de este sarcófago a Tui, es evidente la importancia que reviste la presencia de esta pieza en la ciudad. Su singularidad dentro del conjunto tudense, ya sea como parte del fenómeno del comercio y transporte de materiales desde el ámbito emeritense en época tardorromana o posterior, y los datos derivados del estudio arqueométrico, aportan nueva luz a la interpretación de esta pieza y realzan de forma significativa su interés como reflejo de los flujos y movimientos de materiales marmóreos desde diversos puntos de la Península y en distintos periodos, posiblemente dentro de las redes vinculadas a los elementos de prestigio que se configuraron en el norte de la Península. Dicho fenómeno testimonia nuevamente la inclusión del Noroeste peninsular dentro de los ejes de comunicación y movilidad de este tipo de piezas a lo largo de la historia, dando posible respuesta a diferentes intereses y motivaciones políticas, económicas y sociales, en muy distintos contextos.

\section{Agradecimientos}

Este trabajo se enmarca en el Proyecto Marmora Galicia, coordinado por las Dras. S. González Soutelo y A. Gutiérrez Garcia-M., dentro de los proyectos de investigación «La explotación y comercio de los recursos naturales en el norte de la Hispania romana: lapis, metalla, aqua» (HAR2011-25011) y «Officinae lapidariae tarraconenses. Canteras, talleres y producciones artísticas en piedra de la provincia Tarraconensis») (HAR2015-65319-P), financiados por el Ministerio de Economía y Competitividad y el Fondo Europeo de Desarrollo regional (FEDER); y los proyectos «Marmora et lapides Hispaniae: exploitation, usages et distribution des resources lithiques de l'Espagne romaine» y «Graver dans le marbre: Routes et Origine des Marbres Antiques d'Aquitaine et d'Espagne (ROMAE)» del LabEx Sciences Archéologiques de Bordeaux, programa financiado por la ANR ( ${ }^{\circ}$ ANR-10-LABX-52).

Para este estudio en concreto, queremos agradecer las facilidades dadas por el responsable de Patrimonio de la Diócesis Tui-Vigo y Director del Museo Diocesano, D. Andrés Palomera; así como al Servizo de Patrimonio y Servizo de Museos de la Xunta de Galicia, por su interés y apoyo a este proyecto.

Agradecemos también a los revisores de este artículo sus sugerencias, así como a los profesores S. Vidal, V. García-Entero y P. Lapuente, por sus comentarios; a la profesora I. Mañas Romero, por la aportación de material gráfico; a M. Brilli, por el análisis isotópico de la muestra, realizado en el Laboratorio di Isotopi stabili 
del Istituto di Geologia Ambientale e Geoingegneria IGAG-CNR); y a la doctoranda M.-C. Savin, miembro del proyecto Marmora Galicia, por compartir datos inéditos de su tesis doctoral "Les marbres du Nord-Ouest de l'Espagne (actuelle Galice): contribution à l'étude de leur exploitation et usage durant l'époque romaine et le haut Moyen-Âge par l'apport de la caractérisation archéométrique", dirigida por P. Lapuente (Universidad de Zaragoza) y R. Chalpoulie (IRAMAT-CRP2A UMR 5060 CNRS-Université Bordeaux Montaigne).

\section{BIBLIOGRAFÍA}

Antonelli, F.; Lazzarini, L.; Cancelliere, S. y Dessandier, D. (2009): "Volubilis (Meknes, Morocco): Archaeometric study of the white and coloured marbles imported in the Roman age". Journal Cultural Heritage 10: 116-123. DOI: https://doi.org/10.1016/j. culher.2008.04.006

Antonelli, F.; Lapuente, P. y Dessandier, D. (2015): "Petrographic characterization and provenance determination of the crystalline marbles used in the Roman city of Banasa (Morocco): new data on the import of Iberian marble in Roman North Africa". Archaeometry 57: 405-425. DOI: 10.1111/ arcm.12099.

Arias Vilas, F. (1991): "Sartego do Conde Santo", en Galicia no Tempo. Catálogo da Exposición: 129130. Santiago de Compostela, Xunta de Galicia.

Attanasio, D.; Brilli, M. y Ogle, N. (2006): The isotopic signature of classical marbles, Studia Archaeologica 145. Rome, "L’Erma” di Bretschneider.

Attanasio, D.; Bruno, M.; Prochaska, W. y Yavuz, A.B. (2015): "A multi-method database of the black and White marbles of Göktepe (Aphrodisias), including isotopic, EPR, trace and petrographic data". Archaeometry 57, 2: 217-245.

Ávila y la Cueva, F. (1852): Historia civil y eclesiástica de la ciudad de Tuy y su obispado. Ed. facs. Santiago de Compostela, Consello da Cultura Galega.

Barbin, V.; Ramseyer, K.; Decrouez, D. y Herb, R. (1989): "Marbles blancs: caractérisation par cathodoluminescence". Comptes-Rendus Académie des Sciences Paris 308, II: 861-866.

Barbin, V.; Ramseyer, K.; Decrouez, D.; Burns, S.J.; Chamay, J. y Maier, J.L. (1992): “Cathodoluminescence of white marbles: an overview". Archaeometry 34: 175-183. DOI: 10.1111/j.1475-4754.1992. tb00490.x
Blanc, Ph. (1996): "La cathodoluminescence quantitative des marbres blancs", en 119 e Cong. Nat. Soc. Hist. Scient., Carrières et constructions III: 489504. Amiens (1994), Paris, Éditions du CTHS.

Blanc, Ph. (1999): “Quantification de la cathodoluminescence des marbres blancs et de leurs mineraux accessoires", en M. Schvoerer (ed.), ASMOSIA IV. Actes de la Conférence Internationale. Archéomatériaux-Marbres et autres roches: 45-54. BordeauxTalence (1995), Talence, Centre de Recherche en Physique Appliquée à l'Archéologie.

Braemer, F. (1986): "Répertoire des gisements de pierres ayant exporté leur production à l'époque romaine", en F. Braemer (ed.), Les ressources minérales et l'histoire de leure exploitation. Colloque international tenu dans le cadre du 108e Congrès national des Sociétés savantes: 287-328. Grenoble (1983), Paris, CTHS.

Burkhard, M. (1993): "Calcite twins, their geometry, appearance and significance as stress-strain markers and indicators of tectonic regime: a review". Journal of Structural Geology 15: 351-368.

Caballero Zoreda, L.; Arce, F. y Utrero, M.A. (2004): "La iglesia de San Torcuato de Santa Comba de Bande (Orense)". Archivo Español de Arqueología 77: 273-318. DOI: https://doi.org/10.3989/ aespa.2004.v77.100.

Cabral, J.M.P.; Vieira, M.C.R.; Carreira, P.M.; Figueiredo, M.O.; Penam T.P. y Tavares, A. (1992): "Preliminary study on the isotopic and chemical characterization of marbles from Alto Alentejo (Portugal)", en M. Waelkens, N. Herz y L. Moens (eds.), Ancient Stones: Quarrying, Trade and Provenance: 191-198. Leuven, Leuven University Press.

Cagnat, R. y Chapot, V. (1916): Manuel d'archéologie romaine. Paris, A. Picard.

Canto, A.M. (1977-78): “Avances sobre la explotación del mármol en la España romana”. Archivo Español de Arqueología 50-51: 165-189.

Capedri, S. y Venturelli, G. (2004): “Accessory minerals as tracers in the provenance of archaeological marbles used in combination with isotopic and petrographic data". Archaeometry 46, 4: 517-536. DOI: $10.1111 /$ j.1475-4754.2004.00171.x.

Carlsson-Brandt, E. y Fernández Abella, D. (2013): "Nuevo hallazgo anfórico romano en Tui (Pontevedra)". Gallaecia 12: 257-268. DOI: 10.15304/ gall.32.1473

Casenave, S.; Chapoulie, R. y Villeneuve, G. (2003): "Cathodoluminescence of synthetic and natural calcite: the effects of manganese and iron on orange 
emission”. Mineralogy and Petrology 78: 243-253. DOI: $10.1007 / \mathrm{S} 00710-002-0227-y$

Chavarria Arnau, A. "El final de las villas y las transformaciones del territorio rural en el occidente (siglos V-VIII)", en C. Fernández Ochoa, V. García Entero, F. Gil Sendino (eds.), Villas tardorromanas en Hispania, IV Coloquio Internacional de Arqueologia de Gijón: 193-214. Gijón (2006), Gijón, Trea.

Chivite, X.T. (1964): "Grupo escultórico romano de Mourazos". Cuadernos de estudios gallegos 19, 58 : 137-142.

Cisneros Cunchillos, M. (1988): Mármoles hispanos: su empleo en la España romana. Zaragoza, Universidad de Zaragoza.

Cisneros Cunchillos, M.; Gisbert Aguilar, J. y Somovilla de Miguel, I.A. (2010-2011): "El uso del mármol en la arquitectura de Asturica Augusta”. Anales de Arqueología Cordobesa 21-22: 93-126.

Cueva, F.B. de la (1991): Historia de los monasterios y prioratos anejos a Celanova. M². T. González Balasch (ed. facs.). Granada, Universidad de Granada.

Díaz, P.C.; Martínez Maza, C. y Sanz Huesma, J. (2007): Hispania tardoantigua y visigoda. Madrid, Istmo.

Falque, E. (1994): Historia compostelana. Madrid, Ediciones AKAL.

Fandiño Fuentes, R. (2017): "La traslatio de los santos mártires de Braga a Compostela. Reflexiones sobre el capítulo I, 15 de la Historia compostelana". Cuadernos de Estudios Gallegos 64: 119-140. DOI: https://doi.org/10.3989/ceg.2017.130.04.

Fariña Busto, F. (1991): "Dionysos e Ampelos", en $G a-$ licia no tempo. Santiago de Compostela [exposición]:122-123. Santiago de Compostela, Xunta de Galicia.

Fernández Fernández, A. (2013): O comercio tardoantigo no Noroeste Penínsular: unha análise da Gallaecia sueva e visigoda a través do rexistro arqueolóxico. Noia, Toxosoutos.

Fernández Ochoa, C. y Gil Sendino, F. (2008): "La villa romana de Veranes (Gijón, Asturias) y otras villas de la vertiente septentrional de la cordillera cantábrica”, en C. Fernández Ochoa, V. García Entero, F. Gil Sendino (eds.), Las villae tardorromanas en el Occidente del Imperio: Arquitectura y función. IV Coloquio Internacional de Arqueología en Gijón: 435-480. Gijón (2006), Gijón, Trea.

Fernández Ochoa, C.; Bendala Galán, M.; García-Entero, V. y Vidal Álvarez, S. (2011): “Cubierta de sarcófago con el ciclo de Jonás hallada en Carranque (Toledo)". Archivo Español de Arqueología 84: 231-242. DOI: 10.3989/aespa.084.011.009
Ferreira Priegue, E. (1991): "Las Rutas del comercio medieval: Galicia en las rutas del comercio medieval", en R. Villares (dir.), Historia de Galicia: 425440. Vigo, Faro de Vigo.

Ferrill, D. A.; Morris, A. P.; Evans, M. A.; Burkhard, M.; Groshong Jr. R.H. y Onasch C.M. (2004): "Calcite twin morphology: a low-temperature deformation geothermometer". Journal of Structural Geology Acta 26: 1521-1529. DOI: 10.1016/j.jsg.2003.11.028

Flórez, H. (1765): Viage de Ambrosio de Morales por orden del Rey D. Philipe II a los Reynos de León, y Galicia, y Principado de Asturias para reconocer las reliquias de Santos, sepulcros reales, y libros manuscritos de las Cathedrales, y Monasterios. Madrid, Antonio Marín.

Flórez, H. (1767a): España Sagrada: theatro geográphico-histórico de la iglesia de España: tomo XXII, De la iglesia de Tuy desde su origen hasta el siglo décimo sexto. Madrid, Imprenta Antonio Marín.

Flórez, H. (1767b): España sagrada: theatro geográphico-histórico de la iglesia de España: tomo XXIII, Continuación de las memorias de la santa iglesia de Tuy y colección de los chronicones pequeñas publicados e inéditos de la historia de España. Madrid, Imprenta Antonio Marín.

Fusco, A. y Mañas Romero, I. (2006): Mármoles de Lusitania. Mérida, MNAR.

García-Entero, V. y Vidal Álvarez, S. (2012): "El uso del mármol en el yacimiento de Carranque (Toledo)", en V. García-Entero (ed.), El marmor en Hispania. Explotación, uso y difusión en época romana: 135-154. Madrid, UNED.

González Paz, C.A. (2009): Osorio Gutiérrez, o 'condesanto' de Vilanova de Lourenzá, (Lourenzá, Lugo). Lourenzá, Concello de Lourenzá.

González Soutelo, S. (2007): O Tui antigo: unha aproximación histórica-arqueolóxica. Noia, Toxosoutos.

González Soutelo, S. (2013): Memoria final do estudo correspondente á toma de mostras dos materiais marmóreos de época romana e tardorromana presentes no contexto da Gallaecia. Memoria Arqueológica. Santiago de Compostela, Subdirección Xeral de Conservación e Restauración de Bens Culturais da Xunta de Galicia.

González Soutelo, S. y Cendón Fernández, M. (eds.) (2006): Tui, presente, pasado y futuro: I Coloquio de Historia de Tui. Pontevedra, Diputación de Pontevedra.

González Soutelo, S. y Pérez Losada, F. (eds.) (2014): Tomiño romano: o xacemento de Currás: ano 2014 [exposición]. Tomiño, Concello de Tomiño. 
González Soutelo, S.; Gutiérrez Garcia-M., A. y Royo Plumed, H. (2015): "El mármol de O Incio: Proyecto de caracterización, estudio de la explotación y uso de un marmor local en la Galicia romana", en J.M. Álvarez, T. Nogales e I. Rodà (eds.), Actas XVIII Congreso Internacional de Arqueología Clásica. Centro y Periferia en el mundo clásico I: 323326. Mérida, MNAR.

Gorgoni, C.; Lazzarini, L.; Pallante, P. y Turi, B. (2002): "An updated and detailed mineropetrographic and $\mathrm{C}-\mathrm{O}$ stable isotopic reference database for the main Mediterranean marbles used in Antiquity", en J.J. Herrmann Jr., N. Herz y R. Newman (eds.), ASMOSIA V. Interdisciplinary Studies on Ancient Stone. Proceedings of the 5th International Conference of the Association for the Study of Marble and Other Stones in Antiquity: 115-131. Boston (1998), London, Archetype Publications Ltd.

Gutiérrez Garcia-M., A.; Lapuente P. y Rodà, I. (2012): Interdisciplinary Studies on Ancient Stones. Proceedings of the IX ASMOSIA Conference. Tarragona (2009), Tarragona, ICAC.

Gutiérrez Garcia-M., A.; Royo Plumed, H.; González Soutelo, S.; Savin, M.-C.; Lapuente, P. y Chapoulie, R. (2016): "The marble of O Incio (Galicia, Spain): quarries and first archaeometric characterisation of a material used since Roman times." Archéometrie 40: 103-117. DOI: 10.4000/archeosciences.4783

Habermann, D.; Neuser, R.D. y Richter, K. (1998): “Lower limit of Mn2+-activated cathodoluminescence of calcite: state of art". Sedimentary Geology 116: 13-24. DOI: doi.org/10.1016/S0037-0738(97)00118-8

Herrmann Jr.; Herz, N. y Newman, R. (eds.) (2002): ASMOSIA V. Interdisciplinary Studies on Ancient Stone. Proceedings of the Fifth International Conference of the Association for the Study of Marble and Other Stones in Antiquity. London, Archetype Pub.

Herz, N. (1955): "Petrofabrics and classical archaeology". American Journal of Science 253: 299-305. DOI: 10.2475/ajs.253.5.299.

Herz, N. (1987): "Carbon and oxygen isotopic ratios: a data base for Classical Greek and Roman marble". Archaeometry 29: 35-43.

Herz, N. y Waelkens, M. (eds.) (1988): Classical Marble: Geochemistry, Technology, Trade. ASMOSIA I. Applied Sciences 153. NATO Science Series E, 153. Luca (1988), Boston, Springer Science. DOI: 10.1007/978-94-015-7795-3.

Iglesias Almeida, E. (1988): Notas históricas del Bajo Miño: puertos, barcas, pesqueras. Tui, Museo y Archivo Histórico Diocesano.
Jockey, Ph. (ed.) (2009): ASMOSIA VIII. Interdisciplinary Studies on Mediterranean Ancient Marble and Stones. Proceedings of the 8th International Conference of the Association for the Study of Marble and Other Stones in Antiquity. Collection L'atelier méditerranéen, Maison méditerranéenne des sciences de l'homme. Aix-en-Provence (2006), Paris, Maisonnueve \& Larose.

Lapuente, P. (1995): "Mineralogical, petrographical and geochemical characterization of white marbles from Hispania", en Y. Maniatis, N. Herz y Y. Basiakos (eds.), ASMOSIA III. The Study of Marble and Other Stones Used in Antiquity: 151-160. Athens (1993), London, Archetype Books. DOI: 10.13140/RG.2.1.1854.4168.

Lapuente, P. (2014): “Archaeometry on stones. Multimethod approach to investigate stone provenance. Studied cases from Roman Hispanic marmora", en Archaeometry Workshop 2014/XI./3: 149-158.

Lapuente, P. y Álvarez, A. (2012): "Métodos para la identificación de los mármoles", en V. García-Entero (ed.), El marmor en hispania: explotación, uso y difusión en época romana: 73-90. Madrid, UNED.

Lapuente, P. y Turi, B. (1995): "Marbles from Portugal: Petrographic and isotopic characterization". Science and Technology for Cultural Heritage 4, 2: 33-42.

Lapuente, P.; Álvarez, A. y Royo, H. (2015): "Métodos analíticos en el estudio del mármol estatuario. ¿Es local o importado?", en J.M. Álvarez, T. Nogales e I. Rodà (eds.), Actas XVIII Congreso Internacional de Arqueología Clásica. Centro y Periferia en el mundo clásico I: 53-56. Mérida, MNAR.

Lapuente, P.; Turi, B. y Blanc, Ph. (2000): "Marbles from Roman Hispania: stable isotope and cathodoluminescence characterization". Applied Geochemistry 15: 1469-1493. DOI: 10.1016/S08832927(00)00002-0

Lapuente, P.; Nogales-Basarrate, T.; Royo, H. y Bri1li, M. (2014): "White marble sculptures from the National Museum of Roman Art (Mérida, Spain): sources of local and imported marbles". European Journal of Mineralogy 26: 333-354.

Lapuente, P.; Royo, H.; Brilli, M. y Cuchí, J.A. (2016): "Mármoles escultóricos romanos del patrimonio de Aragón. Nuevas aportaciones arqueométricas", en Actas I Congreso CAPA. Arqueología y Patrimonio Aragonés: 539-548. Zaragoza (2015), Zaragoza, Colegio oficial de Doctores y Licenciados en Filosofía y Letras y en Ciencias de Aragón.

Lapuente, P.; Nogales-Basarrate, T.; Royo, H.; Brilli, M. y Savin, M-.C. (en prensa): "Grey and greyish 
banded marbles from the Estremoz Anticline in Lusitania", en Proceedings of the ASMOSIA XI International Conference. Split (2015).

Lazzarini, L. (ed.) (2002): Interdisciplinary Studies on Ancient Stone. ASMOSIA VI, Proceedings of the Sixth International Conference of the Association for the Study of Marble and Other Stones in Antiquity. Padova, Bottega d'Erasmo Aldo Ausilio Editore.

Lazzarini, L.; Moschini, G. y Stievano, B.M. (1980): "A contribution to the identification of Italian, Greek and Anatolian marbles through a petrographical study and the evaluation of the $\mathrm{Ca} / \mathrm{Sr}$ ratio". Archaeometry 22: 173-183.

Lopes Frazão da Silva, A.C. (2017): "Uma diocese de fronteira em busca de um santo patrono: a promoção do culto a Pedro González em Tui no século XIII". Madrygal. Revista de Estudios Gallegos 20: 211 222. DOI: http://dx.doi.org/10.5209/MADR.56234.

Maciel, M.J. (1998): “Arte romana e pedreiras de mármore na Lusitânia: novos caminhos de investigação". Revista da facultade de Ciencias Sociais e Humanas 11: 233-245.

Machel, H.G. (1985): "Cathodoluminescence in calcite and dolomite and its chemical interpretation". Geoscience Canada 12: 139-147.

Machel, H.G.; Mason, R.A.; Mariano, A.N. y Mucci, A. (1991): "Causes and emission of luminescence in calcite and dolomite", en C.E. Barker y O.C. Kopp (eds.), Luminiscence microscopy and spectroscopy: qualitative and quantitative applications 25: 37-57. Tulsa, Society for Sedimentary Geology (SEPM), DOI: https://doi.org/10.2110/scn.91.25.0009.

Maniatis, Y. (ed.) (2009): ASMOSIA VII. Proceedings of the 7th International Conference of Association for the Study of Marble and Other Stones in Antiquity. Bulletin de Correspondance Hellénique 51. Thassos (2003), Athens, École Française d'Athènes.

Maniatis, Y.; Herz, N. y Basiakos, J. (eds.) (1995): The Study of Marble an Other Stones Used in Antiquity, ASMOSIA III Athens: Transactions of the 3rd International Symposium of the Association for the Study of Marble and Other Stones used in Antiquity. London, Archetype Publications.

Mañas Romero, I. (2012): "Marmora de las canteras de Estremoz, Alconera y Sintra: su uso y difusión", en V. García-Entero (ed.), El marmor en hispania: explotación, uso y difusión en época romana: 331346. Madrid, UNED.

Mañas Romero, I. y Fusco, A. (2008): "Canteras de Lusitania. Un análisis arqueológico”, en T. Nogales Basarrate y J. Beltrán Fortes (eds.), Marmora
Hispana: Explotación y uso de los materiales pétreos en la Hispania romana: 483-500. Roma, "L'Erma" di Bretschneider.

Martínez Tamuxe, X.; Gómez Sobrino, J. y González Santiso, A. (1977): "Necrópolis germánica en el claustro de la Catedral de Tuy". Museo y Archivo Histórico Diocesano 2: 157-159.

Mateos Cruz, P. (1999): La Basílica de Santa Eulalia de Mérida: arqueología y urbanismo. Anejos de Archivo Español de Arqueología XIX. Madrid, Editorial CSIC - CSIC Press.

Moens, L.; De Paepe, P. y Waelkens, M. (1992): "Multidisciplinary research and cooperation: keys to a successful provenance determination of white marble", en M. Waelkens, N. Herz, y L. Moens (eds.), Ancient Stones: Quarrying, Trade and Provenance, Archaeologica Lovaniensia Monographiae 4: $247-$ 254. Leuven, Leuven University Press.

Moens, L.; Roos, P.; De Rudder, J.; De Paepe, P.; van Hende, J. y Waelkens, M. (1988): “A multi-method approach to the identification of white marbles used in antique artifacts", en N. Herz, y M. Waelkens (eds.), Classical Marble: Geochemistry, Technology, Trade, ASMOSIA I, Applied Sciences 153: 243-250. NATO ASI Series 153. Luca (1988), Boston, Dordrecht, Kluwer Publ. Co.

Museo Arqueolóxico Provincial de Ourense (1999): "Peza do mes: Dionysos e Ampelos", Peza do mes, novembro 1999. Ourense, Museo Arqueolóxico Provincial de Ourense.

Museo Arqueolóxico Provincial de Ourense (2006): "Dionisos e Ampelos", en Unha escolma de escultura. Museo Arqueolóxico Ourense: 93-94. Ourense, Museo Arqueolóxico de Ourense.

Naveiro López, J.L. (1991): El Comercio antiguo en el N.W. peninsular: lectura histórica del registro arqueológico. Brigantium 5. A Coruña, Museo Arqueolóxico de $\mathrm{S}$. Antón.

Nogales, T.; Lapuente, P. y Rodà, I. (2017): "Dos nuevos retratos de Caesar Augusta (Zaragoza)", en Actes XIV Colloque International sur l'Art Provincial Romain. June 2015, Dijon, France. Iconographie du quotidien dans l'art provincial romain: Modèles régionaux, 44e suppl. à la Revue Archéologique de l'Est: 261-270. Dijon (2015), Dijon, Société archéologique de l'Est.

Oleiro, J.M.B. (1996): “Das arcas da memória”. Portugalia, Nova Serie XVII-XVIII: 167-170.

Pensabene, P. y Gasparini E. (ed.) (2015): Interdisciplinary Studies on Ancient Stone. ASMOSIA X. Proceedings of the Tenth International Conference of 
ASMOSIA, Association for the Study of Marble \& Other Stones in Antiquity. Rome (2012), Rome, "L'Erma" di Bretschneider.

Pérez Losada, F. (2002): Entre a cidade e a aldea: estudio arqueohistórico dos "aglomerados secundarios" romanos en Galicia. Brigantium, 13. A Coruña, Museu Arqueolóxico e Histórico da Coruña.

Pérez Losada, F.; Fernández Fernández, A. y Vieito Covela, S. (2008): “Toralla y las villas marítimas de la Gallaecia atlántica: emplazamiento, arquitectura y función”, en C. Fernández Ochoa, V. García-Entero y F. Gil Sendino (eds.), Las villae tardorromanas en el occidente del Imperio: arquitectura y función Coloquio Internacional de Arqueología en Gijón: 482-506. Gijón (2006), Gijón, Trea.

Rodríguez Colmenero, A. (1993): Galicia. Arte prehistórica e romana. Ed. en galego. Vol. IX. A Coruña, Hércules.

Rodríguez Oliva, P. (2001): “Talleres locales de sarcófagos en la Bética”, en M.E. Conde y J.M. Noguera (eds.), El sarcófago romano: contribuciones al estudio de su tipología, iconografía y centro s de producción: actas de las Jornadas de Estudio: 129-156. Murcia (2000), Murcia, Servicio de Publicaciones.

Royo, H. (2016): Mármoles de la Cordillera Pirenaica: afloramientos norpirenaicos y asociados al "Nappe des Marbres". Caracterización y uso en época romana. Universidad de Zaragoza, tesis doctoral inédita.

Russell, B. (2011): "The Roman sarcophagus 'Industry': a reconsideration”, en J. Elsner y J. Huskinson (eds.), Life, Death and Representation. Some New Work on Roman Sarcophagi: 119-47. Berlin and New York, De Gruyter.

Russell, B. (2013): The Economics of Roman Stone Trade. Oxford, Oxford University Press.

Sánchez Pardo, J.C. (2015): "El reúso de materiales y estructuras antiguas en las iglesias altomedievales de Galicia. Casos, problemas y motivaciones." Estudos do Quaternário 12: 95-110. http://www.apeq. pt/ojs/index.php/apeq.

Schvoerer, M. (ed.) (1999): Archeomatériaux. Marbres et autres roches. Actes de la IVe Conférence internationale ASMOSIA IV. Bordeaux-Talance (1995), Bordeaux, Presses Universitaires de Bordeaux.

Seara, I. (ed.) (2015): La Catedral de Tui: desde su Plan Director. Santiago de Compostela, Xunta de Galicia, Turismo de Galicia.

Sotomayor Muro, M. (1991): "La presencia del cristianismo: los sarcófagos de Temes y Lourenzá en su contexto", en Galicia no tempo: 57-73. Santiago de Compostela, Xunta de Galicia.
Suárez Otero, J. (2003): "Del Locus Sancti Iacobi al Burgo de Compostela.", en E. Portela Silva (coord.), Historia de la ciudad de Santiago de Compostela: 49-77. Santiago de Compostela, Servicio de Publicaciones.

Vidal Álvarez, S. (2007): "Nuevos datos para el estudio de la producción de sarcófagos del noroeste de la península Ibérica entre los siglos IV-VI: el sarcófago de Portosín (A Coruña) y los relieves de Gijón (Asturias)", en G. Koch (ed.), Akten des Symposiums des Sarkophag-Corpus: 215-231. Marburg (2001), Mainz am Rheim, Verlag Philipp von Zabern.

Vidal Álvarez, S. (2016): “Análisis arqueométricos del sarcófago de Pueblanueva (Toledo) y estudio de cinco fragmentos de sarcófago procedentes de Pueblanueva en las colecciones del Museo Arqueológico Nacional". Boletín del Museo Arqueológico Nacional 34: 195-210.

Vidal Álvarez, S. y García-Entero, V. (2015): “The use of Estremoz marble in late antique sculpture of Hispania: new data from the petrographic and cathodoluminescence analyses", en P. Pensabene y E. Gasparini (eds.), ASMOSIA X. Proceedings of the Tenth International Conference Interdisciplinary Studies on Ancient Stone: 355-366. Rome, "L'Erma” di Bretschneider.

Vidal Álvarez, S.; García-Entero, V. y Gutiérrez Garcia-M., A. (2016): "La utilización del mármol de Estremoz en la escultura hispánica de la antigüedad tardía: los sarcófagos". DigitAR. Digital Journal of Archaeology, Architecture and Arts 3: 119128. DOI: 10.14195/2182-844x_3_14.

Waelkens, M.; Herz, N. y Moens, L. (eds.) (1992): Ancient Stones: Quarrying, Trade and Provenance. Interdisciplinary Studies on Stones and Stone Technology in Europe and Near East from the Prehistoric to the Early Christian Period. Includes papers from the second meeting of ASMOSIA II at the Catholic University of Leuven. Acta Archaeologica Lovaniensia, Monographiae 4. Leuven (1990), Leuven, Leuven University Press.

Ward-Perkins, J. (1980a): "Nicomedia and the marble trade". Papers of the British School at Rome 48: 23-69.

Ward-Perkins, J. (1980b): "The marble trade and its organization: evidence from Nicomedia", en J. D'Arms y E.C. Kopff (eds.), The Seaborne Commerce of Ancient Rome: Studies in Archaeology and History. Memoirs of the American Academy in Rome 36: 325-336. Rome, American Academy in Rome.

Weiss, L.E. (1954): "Fabric analysis of some Greek marbles and its applications to archaeology". American Journal of Science 252: 641-662. 